\title{
Review Article \\ Functions, Cooperation, and Interplays of the Vegetative Growth Signaling Pathway in the Aspergilli
}

\author{
Tünde Pusztahelyi and István Pócsi \\ Department of Microbial Biotechnology and Cell Biology, Faculty of Science and Technology, \\ University of Debrecen, Debrecen 4032, Hungary \\ Correspondence should be addressed to Tünde Pusztahelyi; pusztahelyi@yahoo.com
}

Received 28 April 2013; Revised 31 July 2013; Accepted 18 August 2013

Academic Editor: Thierry Jouault

Copyright (C) 2013 T. Pusztahelyi and I. Pócsi. This is an open access article distributed under the Creative Commons Attribution License, which permits unrestricted use, distribution, and reproduction in any medium, provided the original work is properly cited.

Knowledge on the functions, cooperation, and interplays of the signaling and regulatory pathways of filamentous fungi is crucial when their industrial performance is improved or when new-type antifungals are developed. Many research groups aim at a deeper understanding of vegetative growth signaling because this cascade also influences other important physiological processes including asexual and sexual developments, autolysis and apoptotic cell death as well as the production of a wide array of important secondary metabolites. This review also focuses on how this signaling pathway is interconnected with other signaling cascades setting up a robust but delicately regulated signaling network in the Aspergilli.

\section{Introduction}

Almost $50 \%$ of the known fungi and around $80 \%$ of the human pathogen fungi are phylogenetically related to Ascomycetes [1]. Moreover, many species of the Aspergilli possess medical and/or industrial importance; for example, they have large capacities of extracellular hydrolytic enzyme, food ingredient, or antibiotic productions [2]. Considering the most studied species within this genus, Aspergillus niger can play a role as an opportunistic pathogen in humans [3], though its real importance is in industrial-scale citric acid production [4], which is higher than one million tons per year [5]. A. oryzae is a well-known "generally regarded as safe" (GRAS) organism in food fermentation industry, for example, in traditional sake, tofu, and acetic acid productions. A. fumigatus is a specialized opportunistic human pathogen, which is a saprophytic organism [6-8] with airspread conidiospores $[9,10]$. It is characterized by abundant spore production as, from every conidiophore, thousands of small (2-3 $\mu$ m diameters) conidia are released and are able to reach the alveoli in lungs [11]. With increase in number of immunosuppressed patients and modern immunosuppressing therapies [12-14], this fungus became very dangerous especially in developing countries [15-19]. Although A. fumigatus is considered as the most dangerous fungus causing higher than $90 \%$ of human aspergilloses $[8,20-24]$, other species are also potential pathogens; for example, $A$. flavus, $A$. terreus, $A$. niger and even $A$. nidulans can also cause human illnesses [24]. Moreover, A. nidulans is a well-known genetic model organism within the Aspergilli with an enormous background database (http://www.aspgd.org/) on its genetic and biochemical properties.

\section{Vegetative Growth Signaling}

The growth of $A$. nidulans is regulated via the FadAdependent signal transduction pathway, where FadA is part of a heterotrimeric $[\operatorname{FadA}(\mathrm{G} \alpha):: \operatorname{SfaD}(\mathrm{G} \beta):: \mathrm{GpgA}(\mathrm{G} \gamma)]$ Gprotein $[25,26]$. All heterotrimeric G-proteins, which are functionally well conserved in the Aspergilli, have a central role in physiological and biochemical responses to various external stresses. When FadA is in an active GTP-bound state and the heterotrimer has disassociated to FadA-GTP and $\mathrm{SfaD}:: G p g A$ dimer, they activate an array of downstream effectors and initiate and maintain vegetative growth [2527] partly through PkaA cAMP-dependent protein kinase A $[28,29]$, while downregulate asexual and sexual development and sterigmatocystin (ST) production (Figure 1).

Growth signaling through FadA is regulated by FlbA RGS protein [30]. G-protein signal transduction pathway 


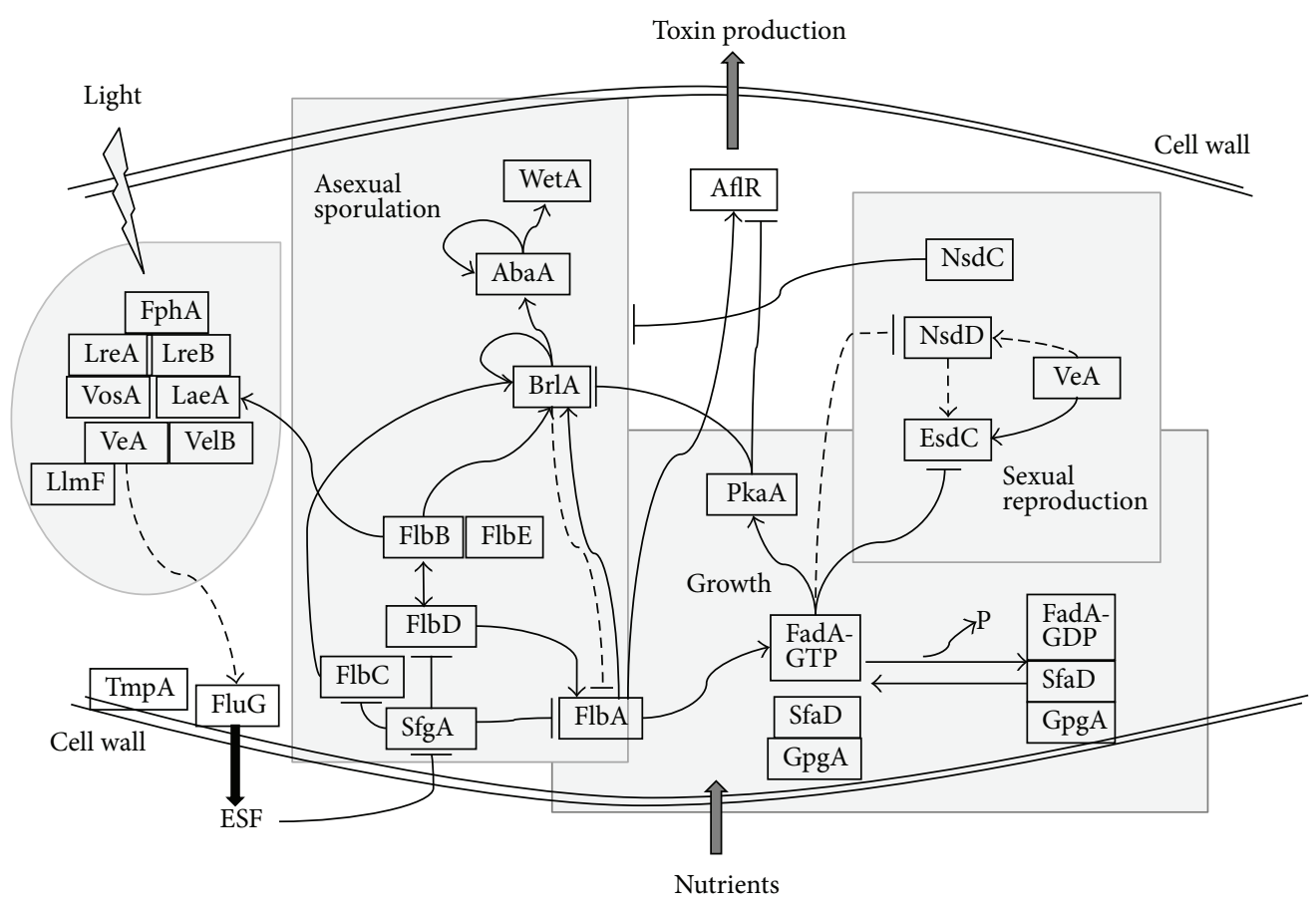

FIGURE 1: Schematic picture of the cooperation network and interplays of the vegetative growth signaling pathway with the asexual and sexual development signal transduction pathways. Connections to the velvet complex, especially to VeA, are also presented. AflR, the regulatory transcription factor of toxic sterigmatocystin/aflatoxin biosynthesis, is also connected to vegetative growth signaling through PkaA. ESF: extracellular sporulation factor; P: phosphorous.

regulators (RGS: regulators of G-protein signaling) have enormous importance out of the several other regulatory mechanisms [26]. Active $f l b A$ regulates negatively mycelial growth [25-27] and supports asexual conidiophore development [29, 30] (Figure 1) by significantly increasing FadAGTPase activity, and, therefore, FadA-GTP rapidly converts to FadA-GDP inactive form [30]. In A. fumigatus, FlbAmediated signaling also controls the expression and activity of gliotoxin oxidoreductase/thioredoxin reductase (GliT) and exhibits enhanced tolerance to gliotoxin toxicity [31]. Moreover, the FlbA-mediated control of growth signaling results in the downregulation of cellular responses associated with detoxification of reactive oxygen species (ROS) as the $f l b A$ deletion mutant strain displays enhanced superoxide dismutase activity and increased resistance to oxidative stress caused by menadione and paraquat [31]. The requirement for FlbA in asexual sporulation could be bypassed by gene deletion of a phosducin-like protein $(p h n A)$, indicating that PhnA functions in FlbA-controlled vegetative growth signaling. PhnA is part of the SfaD::GpgA mediated signaling, which is needed for normal proliferation, sexual sporulation, ST production, and the inhibition of asexual conidiogenesis [32].

\section{Asexual Sporulation}

Conidiation is a common and complex process in the Aspergilli, where large numbers of conidia (asexual spores) develop on conidiophores $[29,33,34]$. Conidia are characterized with low metabolic activity and water content $[33,35]$. Two phases of the asexual reproduction cycle can be separated, vegetative growth and development. After germination of a conidium, ascomycetous colony is formed, which consists of apically pluripotent hyphae that grow radially and produce undifferentiated filaments called mycelia [33, 35]. Behind the peripheral area in superficial hyphae, changes in gas concentrations $\left(\mathrm{O}_{2} / \mathrm{CO}_{2}\right.$ ratio) [36] and illumination [37] induce differentiation and conidiophore development. Any stress conditions like nutrient shortage, osmotic or salt stress [37-39], which do not support growth, induce conidiophore development, which itself deeply affects the metabolic pattern of the colonies through increasing secondary metabolite production in aerial hyphae and intensifying autolytic processes [37, 40]. The early regulator of the conidiophore development is $\mathrm{BrlA}$, a $\mathrm{C}_{2} \mathrm{H}_{2}$-type zinc finger transcription factor [33, 41]. Activation of $b r l A$ is crucial in conidiophore development and conidia production. BrlA as well as the downstream AbaA [42, 43] and WetA [44] transcription factors together fulfill the role of the central regulatory pathway of conidiation [44-46] (Figure 1), which affects conidiophore development and transcription of genes required for conidiogenesis $[29,33,46]$. The proper timing of the expression of the regulators is of pivotal importance for the proper conidiophore development [46]. At any culture time, increased brlA expression activates simple conidiophore development with conidiospore production [41]. The expression of brlA in vegetative cells leads to 
the activation of $a b a A$ and wetA genes, the cessation of vegetative growth, cellular vacuolization, and conidiogenesis [44]. Importantly, expression of $a b a A$ in vegetative cells does not result in conidial differentiation but leads to activation of $b r l A$ and wetA, cessation of vegetative growth, and accentuated cellular vacuolization [44]. Upstream of BrlA, a set of Flb proteins, FlbB [47, 48], FlbC [49], FlbD $[50,51]$, and FlbE [52], can be localized (Figure 1), which all regulate brlA gene activity. Besides having role in signal transduction in nuclei, FlbB and FlbE are also functioning as a dimeric sensor protein at hyphal apices [53]. In the nuclei, $\mathrm{FlbB}$ and FlbE are necessary for the proper laeA (a nuclear regulator from the velvet complex (reviewed in [54])) expression, gliotoxin production [47], and the virulence of $A$. fumigatus [55]. The velvet complex is a conserved fungal transcriptional heteromer that couples regulation of secondary metabolism with sexual development in fungi. The function of the $f l b$ genes is under FluG activity $[29,33-35,46,56-59]$ and velvet complex regulation $[29,46]$ (Figure 1) control. Intensive research revealed a high homology between the conidiophore development regulatory pathways in A. nidulans and A. fumigatus, where the elements of the central conidiation regulatory pathway and their regulation through BrlA were identical but the upstream regulatory elements were different $[57,58]$. In $A$. oryzae, investigation of deletion mutants of the $f l u G$, $f l b B, f l b C, f l b D, f l b E, b r l A, a b a A$, and wetA homologues proved that the activities of the deleted genes are essential for the conidiogenesis [59], similar to A. nidulans. The $\mathrm{Ca}^{2+}$-dependent CnaA/CalA-CrzA (calcineurin and a $\mathrm{C}_{2} \mathrm{H}_{2}$-type transcription factor) regulatory pathway of cation homeostasis maintenance also strongly affects conidiogenesis as well as cell wall structure [60-63]. Both the vegetative growth and the asexual development of the $\triangle c r z A$ mutants were hypersensitive to increased calcium concentrations in A. parasiticus [64]. The A. fumigatus $\triangle c r z A$ mutants had reduced asexual sporulation with decreased AfbrlA and AfwetA gene expressions during asexual development, which indicated possible calcineurin-dependent functions $[61,65]$. Interplay between cation homeostasis maintenance and vegetative growth signaling via the $\mathrm{SfaD}(\mathrm{G} \beta)$ subunit of the heterotrimeric G-protein and the FlbA RGS protein was also demonstrated in $A$. nidulans, where deletion of $s f a D$ suppressed reduced conidiation observed in a $\triangle c n a A$ mutant strain [62].

\section{Regulation of the Switch from Vegetative Growth to Conidiation}

Regulatory elements building up response to environmental changes, regulating vegetative growth cessation, and being responsible for the induction of autolysis and secondary metabolite production were also identified (reviewed by [29, 46]). Conidiation in A. nidulans is induced by exposure to red light but can also be induced by blue light in certain mutant strains [66-68]. The VeA protein from the velvet complex (Figure 1) [37] integrates red and blue light signals, regulates developmental response to light [37,66-68], and affects asexual and sexual reproduction $[37,66]$. VeA is a global regulator of sclerotia and secondary metabolite productions $[46,66]$, and it is also important in the biosynthesis of mannoproteins [69]. FluG codes for a constitutive cytoplasmic protein that shows high homology with prokaryotic glutamine synthetase I [70], and it produces highly diffusible compounds like dehydroaustinol and other yet unidentified molecules in A. nidulans [71]. Presumably, TmpA, a membrane-bound oxidoreductase is also involved in the synthesis of the developmental signal molecules [72]. Recently, an interaction between $f l u G$ and VeA was proposed, which influence the production of the signal molecules and, hence, may regulate the initiation of conidiation [73]. Meanwhile the effect of VeA on autolysis and vegetative growth through the modulation of $f l u G$ gene expression has remained presumptive [46], VeA controls the expression of the conidiation-regulatory gene brlA [68]. The veA1 mutation, which allows asexual development in the dark, was suppressed by mutations in the $f l u G$ locus, and these double mutants did not form conidia in the absence of light $[73,74]$. Under conditions which promote conidiation in the veAl suppressors, no extracellular conidiation signal could be detected [73]. In A. flavus, such extracellular meroterpenoids were not found, suggesting that the function of FluG and the signaling pathways related to conidiation are different in the two Aspergillus species [75]. Extracellular dehydroaustinol, assisted by the orsellinic acid derivative diorcinol [71], is required to inhibit the repressive effect of the transcription factor SfgA on conidiation in A. nidulans [76] (Figure 1). It is worth to mention that transcription factor FlbB was also shown to produce a second and yet unknown diffusible signal, acting downstream from the FluG factor in A. nidulans in the induction of the conidiation [48]. Consequently, the signal molecules activate an array of developmental inducers through the activation of the $f l b C$ and $f l b D$ genes in actively growing cultures [56, 57], which initiate the switch from vegetative growth to conidiation by the upregulation of FlbA RGS protein $[33,56-$ 58]. Another RGS protein, RgsA, also influences positively asexual sporulation and meanwhile downregulates conidial germination through $\mathrm{Gan} B(\mathrm{G} \alpha)$ dependent heterotrimeric G-protein signaling [77]. RicA, which is a putative GDP/GTP exchange factor for G-proteins in A. nidulans and A. fumigatus, can physically interact with GanB, mediates growth and developmental signaling primarily through GanB and PkaA in A. nidulans. The deletion of ricA resulted in severely impaired colony growth and decreased conidiation [78].

Loss of function mutations of $f l u G$ and $f l b A$ resulted in the appearance of undifferentiated mycelia in "fluffy" colonies. However, at least under nutrient deprivation, $f l u G$ mutants still produced some conidia [79], which indicated that the activation of brlA may also occur in a FluG-independent manner. In A. flavus, deletion of $f l u G$ yielded strains with an approximately 3 -fold reduction in conidiation and a 30-fold increase in the formation of sclerotia, indicating that FluG exerts opposite effects on the signaling pathways of these developmental processes. The altered conidial development was attributed partly to the delayed expression of brlA [41, 75]. The nutrient-dependent regulation of conidiation may 
also lead to the derepression of $\operatorname{brlA}[80,81]$, which even in the absence of $f l u G$ is regulated through growth intensity and nutrient availability [70]. The function of FlbA in the regulation of $\operatorname{brl} A$ expression has also been demonstrated because overexpression of $f l b A$ using an inducible promoter resulted in misscheduled expression of $b r l A$ and caused hyphal tips to differentiate into spore-producing structures [82].

\section{Regulation of Sexual Development}

During sexual development two distinct structures are observable in A. nidulans (sexual stage name: Emericella nidulans): Hülle cells and cleistothecia (reviewed in [83]). FadA::SfaD::GpgA heterotrimeric G-protein has a regulatory role in sexual reproduction as well. SfaD::GpgA heterodimer is the primary signaler for sexual development. Dominantly activated fadA mutants do not produce any sexual reproductive formations, and continuously activated FadA and $\mathrm{SfaD}$ growth signaling represses both sexual and asexual development. SfaD $(\mathrm{G} \beta)$ and/or GpgA $(\mathrm{G} \gamma)$ subunits regulate negatively Hülle cell formation $[25,32]$, and, similarly to the $s f a D$ deletion mutant $[25,27]$, the $\triangle g p g A$ mutant of $A$. nidulans is unable to produce any cleistothecia in self-fertilization [25]. The $\triangle g p g A$ mutation suppressed developmental and morphological defects caused by the deletion of $f l b A$ [25]; however, it could not bypass the need for the early developmental activator FluG in asexual sporulation, suggesting that GpgA functions in a separate signaling pathway [25].

$N s d C$ encoding a putative $\mathrm{C}_{2} \mathrm{H}_{2}$-type transcription factor [84] and $n s d D$ coding for a putative GATA type transcription factor [85] are key regulators, which are required for proper sexual development in $A$. nidulans. Their homologs in $A$. flavus are also required for production of asexual sclerotia, normal aflatoxin biosynthesis, and also conidiophore development. Deletion of these genes results in conidiophores with shortened stipes and altered conidial heads [86]. The phnA deletion mutant was severely impaired in sexual reproduction [32], and requirement for PhnA in cleistothecium development was not due to the altered expression of $n s d D$ [85]. The RGS protein FlbA regulates both asexual and sexual development via the activation of $b r l A$ and the derepression of $n s d D$ and/or esdC [85]. The activation of esdC coding for the regulator gene of early sexual development at first needs FadA inactivation, and, later, it is regulated by VeA $[37,68]$ besides the heterotrimeric G-protein [87] (Figure 1). In $A$. nidulans, deletion of $n s d C$ resulted in retardation in vegetative growth and in hyperactive asexual sporulation because NsdC is not only necessary for sexual development but also inhibits asexual sporulation. NsdC regulates sexual development independently of $\mathrm{VeA}$ or NsdD in A. nidulans [84].

\section{Regulation of Autolysis}

Nutrient recycling through autophagy is the first type of starvation-induced programmed cell death before induction of more detrimental cell-death processes such as cellular degradation, autolysis, and apoptotic cell death [88-91]. These processes are energy dependent [40,92], and their regulation is more complex and more sophisticated than that of necrotic cell death processes. Well conserved constitutively active autophagy plays an important role in cellular homeostasis by efficient removal of damaged organelles and the regulation of cell death. Autophagy is strongly induced by the limitation of nutrients including carbon, nitrogen, and oxygen. The induction of autophagy is a hallmark of carbonstarved aging fungal cultures, and carbon recycling can result in secondary growth of viable cells $[80,93]$.

Autolysis has been generally used to describe hallmarks of aging cultures including declining biomass, increasing extracellular ammonia concentration, hyphal fragmentation, and increasing extracellular hydrolase activities [94]. In aging hyphae, vacuolization and increased intracellular and extracellular hydrolytic enzyme activities can be observed, which are followed by the degradation of cell wall constituents and cellular organelles $[94,95]$. Autolysis contributes to the survival of filamentous fungi under harsh environmental conditions like carbon shortage. Cell wall degradation and conidiation processes are coregulated; for example, they are under glucose repression, nutrition sensing, and BrlA control $[38,40,96]$. The main function of autolysis is to supply developmental processes with energy sources $[33,38$, 40]. After prolonged carbon starvation and autophagy cell death precedes the lysis of cell wall, which remains intact even when hyphal compartments became empty [80, 93]. The degradation of cell wall, which is the most important carbon-rich component of fungal cells, makes conidiogenesis possible and helps the population to survive.

Under conditions that hindered asexual conidiation like in submerged culture, the deletion of $f l b A$ gene resulted in accelerated cell death and autolysis in A. fumigatus [31], while yeast-like cells are formed, which may remain viable as cryptic cell in $A$. nidulans $[95,97,98]$. Not surprisingly, the addition of glucose represses autolytic cell wall degradation even in creA null mutant strains of $A$. nidulans [99] through the inhibition of the FluG-dependent signal transduction pathway [40]. The CreA protein, which possesses high homology to Miglp carbon catabolite repressor in $S$. cerevisiae [100], is the main carbon catabolite repressor in A. nidulans and has a regulatory role under both glucose shortage and glucose abundant conditions [101, 102].

As demonstrated by global transcriptome analyses performed in autolyzing cultures of $A$. nidulans, the onset of gross autolysis is preceded by the strong upregulation of an array of genes encoding autolytic hydrolases [81] like glucanases (e.g., EngA 1,3- $\beta$-glucosidase) and chitinolytic enzymes (ChiB, ChiC, and NagA) [96, 103-105]. These activities maintain surviving cells with nutrient and energy sources and also support conidiogenesis. FluG/BrlA conidiation signaling is of crucial importance in the induction of extracellular autolytic enzymes, like the endochitinase ChiB [103, 104] and the endoglucanase EngA [105], under carbon shortage [40]. Glucose and also its antimetabolite 2-dezoxy-D-glucose repress $\mathrm{ChiB}$ production through CreA-dependent and CreA-independent pathways via the downregulation of brlA expression in A. nidulans [96]. In 
A. niger, major secreted hydrolases included PepA protease and NagA $N$-acetyl- $\beta$-D-glucosaminidase but not ChiB endochitinase [80]. Interestingly, in Penicillium chrysogenum, VeA homologue PcVelA or LaeA homologue PcLaeA positively regulated PcchiB1 encoding a class $\mathrm{V}$ chitinase (homologue of ChiB in A. nidulans). Disruption of PcchiB1 resulted in loss of cell wall integrity and pellet formation [106].

\section{Apoptosis}

Programmed cell death (apoptosis) is a common process in filamentous fungi [107] under carbon starvation [96, 98]. Apoptosis eliminates damaged cells by the coordinated activity of gene products that regulate cell death and induce cell proliferation, so that the old cells are replaced [107]. Biochemical markers of apoptosis, including ROS accumulation, DNA cleavage, and externalization of phosphatidylserine, have also been used to detect apoptosis in fungi. Under carbon shortage, the accumulation of ROS, the appearance of apoptotic markers, or the vitality of the cells were affected by neither fluG1 inactive nor creA null-type mutations [96]. Therefore, the regulation of apoptosis and autolytic cell wall degradation are considered to be independent in $A$. nidulans $[40,89]$. In $P$. chrysogenum, autolysis and decreasing metabolic activity were also independent phenomena [92].

There are some data on the involvement of FadAdependent heterotrimeric G-protein signaling in the initiation of apoptotic cell death in $A$. nidulans [108, 109]. The small, basic, and cysteine-rich antifungal protein PAF, which is abundantly secreted into the supernatant by $P$. chrysogenum, inhibited the polar growth of various important filamentous fungi, like $A$. nidulans, causing hyperpolarization of the plasma membrane and activation of ion channels, followed by an increase in the concentrations of ROS in the cells and the induction of an apoptosis-like phenotype. Dominant-interfering mutation in fadA and a pkaA deletion mutant exhibited reduced PAF sensitivity in $A$. nidulans and $\mathrm{PAF}$ activated $\mathrm{PKaA} \mathrm{cAMP} /$ protein kinase $\mathrm{A}$ dependent signaling cascade [110] suggesting that G-protein signaling is involved in the PAF-mediated apoptotic cell death [108, 109].

\section{Secondary Metabolite Production}

Genes for the biosynthesis and regulation of secondary metabolites (e.g., antibiotics, phytotoxins, mycotoxins, and pharmaceuticals) are usually clustered in fungi [111, 112]. Sterigmatocystin (ST) and aflatoxin are related mycotoxins and are among the most toxic, mutagenic and carcinogenic natural products known $[112,113]$. ST biosynthetic pathway [114] is estimated to involve at least 25 enzyme activities coded on one gene cluster in A. nidulans [112], while certain A. parasiticus, A. flavus, and A. nomius strains contain additional activities that convert ST to aflatoxin [111, 115118]. The key regulator of ST/aflatoxin biosynthesis is the $\mathrm{Zn}(\mathrm{II})_{2} \mathrm{Cys}_{6}$ type transcription factor AflR, which regulates further genes in the cluster [119]. The expression of aflR is connected to asexual conidiophore development through transcriptional and posttranscriptional regulations by the heterotrimeric $\operatorname{FadA}(\mathrm{G} \alpha):: \operatorname{SfaD}(\mathrm{G} \beta):: \mathrm{GpgA}(\mathrm{G} \gamma)$ G-proteincAMP-protein kinase A ( $\mathrm{PkaA})$ signaling pathway involving the RGS protein FlbA [120-124]. In the absence of $f l b A$, dominantly activated aflR could not restore ST production in A. nidulans. Mutations in three PkaA phosphorylation sites in AflR allowed resumption of ST gene expressions under overexpression of $p k a A$ but did not remediate ST gene expressions in a $\triangle f l b A$ background [121]. This demonstrates a negative regulation of AflR activity by phosphorylation and shows that the posttranscriptional regulation of aflR by FlbA is PkaA independent [121]. The PkaA protein was described as a regulator of $f l u G$ and $f a d A$ genes and also the conidiophore development $[28,121]$. When PkaA was overexpressed the transcriptions of aflR and $b r l A$ were not induced, which, consequently, resulted in the inhibition of both mycotoxin production and conidiophore development [28]. The heterotrimeric G-protein subunits SfaD and GpgA and the phosducin-like protein PhnA [32] were all necessary for the expression of aflR and ST biosynthesis. FadAmediated signaling resulted in the inhibition of ST biosynthesis by blocking aflR gene expression [120], while dominant activating $\mathrm{fad} A$ allele, $\mathrm{fad} A^{G 42 R}$, stimulated transcription of a gene from the penicillin gene cluster and elevated penicillin production in A. nidulans. Therefore, FadA was proposed to have opposite roles in the regulation of the biosynthesis of penicillin and ST, and it was suggested that targeting Gprotein signal transduction pathways in mycotoxin control or prevention could have serious undesirable effects by the production of other secondary metabolites [123]. In A. parasiticus, the negative regulation of aflatoxin biosynthesis and conidiation by FadA/PKA signaling was also demonstrated [124]. Other G-protein mediated signaling pathways also take part in the regulation of aflatoxin biosynthesis: RgsA, another known RGS protein also stimulated asexual conidiation and ST production by inhibiting GanB ( $\mathrm{G} \alpha)$ heterotrimeric Gprotein subunit [77].

Significant differences in the toxin production machinery were also demonstrated in the Aspergilli. For example, besides AflR, another transcriptional regulator encoded by afl is present in the aflatoxin biosynthetic gene cluster in A. flavus, which is absent in the $A$. nidulans genome. Disruption of the aflJ gene resulted in a failure to produce aflatoxins and to convert exogenously added toxin intermediates, for example, norsolorinic acid and sterigmatocystin, to aflatoxin [125]. In A. parasiticus, AflJ did not regulate aflatoxin biosynthetic genes directly, instead it interacts with full-length AflR but the DNA-binding domain of AflR was found not to be essential for the interaction [126]. In A. nidulans fluG deletion mutant strains, the loss of ST production was detected; meanwhile, in $A$. flavus the aflatoxin biosynthesis was not affected by the fluG deletion [75].

Environmental factors (e.g., light, temperature, $\mathrm{pH}$, calcium, and nutrients) regulate mycotoxin production in a concerted way. The effect of light on the production of sterigmatocystin (ST) depends on glucose concentration. Glucose abundance affects the light-dependent subcellular localization of $\mathrm{VeA}$, and other components of the velvet complex (Figure 1) [93] like the blue-light-sensing proteins 


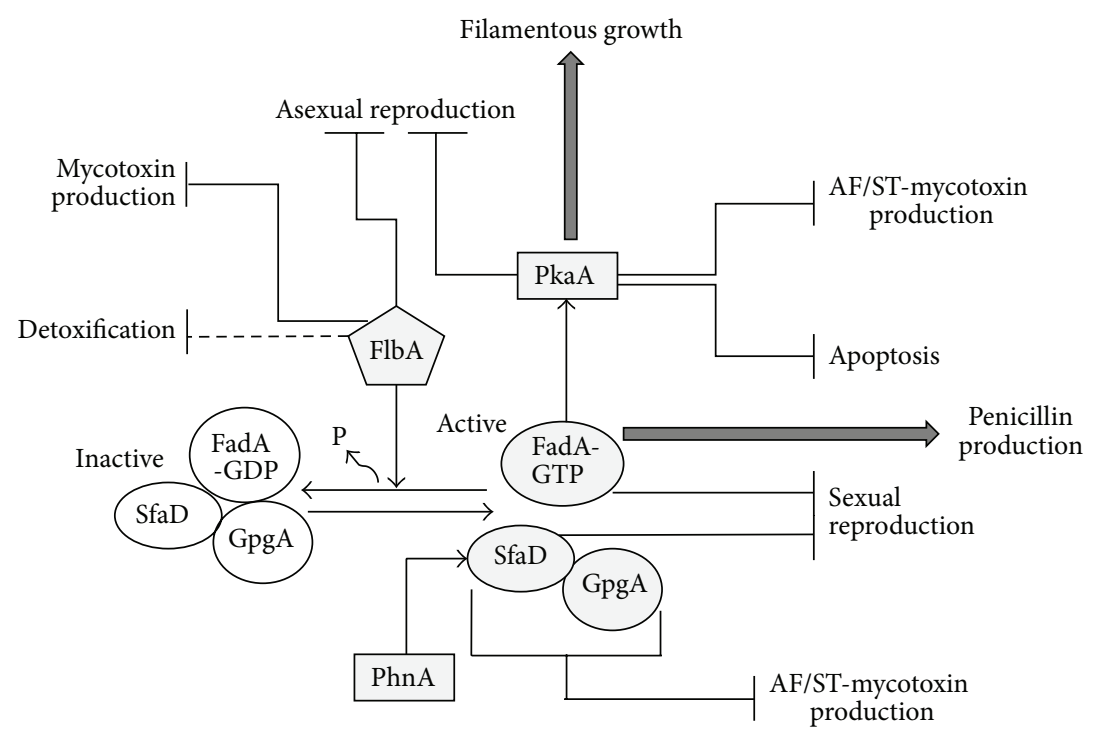

FIGURE 2: Summary of the physiological processes influenced by vegetative growth signaling. The pathway is regulated positively through extracellular sporulation factor(s) (ESF) produced by the FluG protein, which inhibits the activity of the transcriptional regulator SfgA. In the absence of ESF, $f l b A$ expression is repressed by SfgA, and FadA is maintained in its activated form. The active vegetative growth signaling pathway, when the environmental factors are satisfactory, stabilizes filamentous growth of the colonies; meanwhile sexual and asexual reproductions as well as the productions of some secondary metabolites (e.g., aflatoxin/sterigmatocystin, gliotoxin) are repressed and some other ones (e.g., penicillin) are stimulated. P: phosphorous; AF/ST: aflatoxin/sterigmatocystin.

LreA and LreB can also be modified. LreA and LreB as well as the phytochrome FphA protein modulate not only the synthesis of ST [127] but also the production of the antibiotic penicillin $[128,129]$. Deletion of the $v e A$ gene in A. nidulans led to a failure of ST production due to decrease in aflR transcription [129]. Importantly, the transcriptional regulator LaeA, which is a putative methyltransferase [130], negatively affected the expression of $\mathrm{VeA}$ in the velvet complex $[37,129]$, and it has been shown to be a key regulator of the production of multiple secondary metabolites in A. nidulans [129], A. fumigatus [131], and A. flavus [132]. Based on microarray studies, disruption of laeA affected the expression of $9.5 \%$ of the genes in A. fumigatus [131], including the genes required for the production of secondary metabolites $[46,130]$. In $A$. flavus, deletion of laeA resulted in the failure of aflatoxin production although the expression of some early genes involved in aflatoxin biosynthesis was detected but none of the later biosynthetic genes [132]. Interestingly, laeA deletion mutants were still capable of producing ST in A. nidulans [133]. Another regulator protein of the velvet complex LlmF interacts directly with VeA, and the repressive function of $\mathrm{L} \operatorname{lmF}$ is mediated by influencing nuclear or cytoplasmic accumulation of VeA [134].

In a mutagenesis screen for secondary metabolism activation, a Yap-like bZIP, termed restorer of secondary metabolism A (RsmA), has been identified [135]. Overexpression of $r s m A$ was able to partially compensate for loss of LaeA and VeA [136] and resulted in a 100-fold increase in sterigmatocystin and a near loss of meiotic spore production [137].

In the A. flavus laeA deletion mutant the loss of hydrophobicity and other developmental changes could affect the ability of the fungus to produce aflatoxins [75] because changes on the cell surface are likely to affect light signaling [66-68], which is necessary for the initiation of development and G-protein signaling [123]. In A. parasiticus, the polyketide synthase gene pksA (the homolog of the A. nidulans $w A$ gene) is involved in the biosynthesis of conidial cell wall pigments and also catalyzes the formation of the polyketide backbone necessary for aflatoxin biosynthesis [138]. For the proper expression of $p k s A$, an array of cis-acting elements including BrlA (the early activator of asexual conidiation), $\mathrm{PacC}$ (a transcription factor involved in $\mathrm{pH}$ regulation), and CreA (mediates carbon catabolite repression) as well as the pathway-specific transcription factor AflR are all necessary. However, the binding sites for these transcription factors in $p k s A$ promoters are highly variable in aflatoxin-producing fungi $[138,139]$. In addition, the calcium-dependent regulation of aflatoxin biosynthesis is also noteworthy because the relative expression levels of biosynthetic cluster genes decreased significantly in $\triangle c r z A$ mutants of $A$. parasiticus [64].

\section{Summary}

In filamentous fungi, the remarkable complexity of the signaling and regulatory network has been recognized first in the 80s. Since then, genome sequencing and improved molecular biological tools let us get a deeper insight into the fine structure and regulation of the signal transduction cascades and also the cross-connections of these pathways. Nowadays, knowledge on the interplays between the signaling pathways is accumulating fast, and the view that they act in a concerted way to maintain growth, to facilitate 
propagation, or to set into operation cell death programs is becoming more and more widely accepted. In the Aspergilli, vegetative growth signaling through the heterotrimeric FadA $(G \alpha):: S f a D(G \beta):: G p g A(G \gamma)$ G-protein and its regulator FlbA is also connected tightly to signaling cascades regulating asexual and sexual developments, autolysis, and apoptotic cell death and the production of important secondary metabolites including mycotoxins (e.g., ST and aflatoxin) (Figure 2) and antibiotics (e.g., penicillin). Further studies are needed to shed light on the proper organization and regulation of this complex signaling network, which would be of paramount importance to support the metabolic and morphological engineering of industrial strains or to help the development of new-type antimycotics for either biomedical or agricultural use in the genus Aspergillus.

\section{Acknowledgments}

The authors thank Zsuzsanna Kovács and Gábor Kormány for their valuable technical assistance in the preparation of the paper. This work was financially supported by the Hungarian Scientific Research Fund (Grant reference no. K100464).

\section{References}

[1] J. Guarro, J. Gené, and A. M. Stchigel, "Developments in fungal taxonomy," Clinical Microbiology Reviews, vol. 12, no. 3, pp. 454$500,1999$.

[2] C. Knuf and J. Nielsen, "Aspergilli: systems biology and industrial applications," Biotechnology Journal, vol. 7, pp. 1147-1155, 2012.

[3] J. R. Perfect, G. M. Cox, J. Y. Lee et al., "The impact of culture isolation of Aspergillus species: a hospital-based survey of aspergillosis," Clinical Infectious Diseases, vol. 33, no. 11, pp. 1824-1833, 2001.

[4] J. Magnuson and L. Lasure, "Organic acid production by filamentous fungi," in Advances in Fungal Biotechnology for Industry, Agriculture, and Medicine, J. Tkacz and L. Lange, Eds., pp. 307-340, Kluwer Academic \& Plenum, New York, NY, USA, 2004.

[5] S. E. Baker, "Aspergillus niger genomics: past, present and into the future," Medical Mycology, vol. 44, no. 1, pp. 17-21, 2006.

[6] H. van den Bossche, D. W. R. MacKenzie, and G. Cauwenbergh, Eds., Aspergillus and Aspergillosis, Plenum Press, New York, NY, USA, 1988.

[7] J. I. Pitt, "The current role of Aspergillus and Penicillium in human and animal health," Journal of Medical and Veterinary Mycology, Supplement, vol. 32, supplement 1, pp. 17-32, 1994.

[8] J. Haines, "Aspergillus in compost: straw man or fatal flaw," BioCycle, vol. 6, pp. 32-35, 1995.

[9] J. Mullins, R. Harvey, and A. Seaton, "Sources and incidence of airborne Aspergillus fumigatus (Fres)," Clinical Allergy, vol. 6, no. 3, pp. 209-217, 1976.

[10] J. Mullins, P. S. Hutcheson, and R. G. Slavin, "Aspergillus fumigatus spore concentration in outside air: Cardiff and St Louis compared," Clinical Allergy, vol. 14, no. 4, pp. 351-354, 1984.

[11] R. A. Samson and E. S. van Reenen-Hoekstra, Eds., Introduction to Food-Borne Fungi: Centraalbureau Voor Schimmelcultures, Baarn, The Netherlands, 1988.
[12] J. Cohen, D. W. Dennining, and M. A. Viviani, "Epidemiology of invasive aspergillosis in European cancer centres," European Journal of Clinical Microbiology and Infectious Diseases, vol. 12, no. 5, pp. 392-393, 1993.

[13] T. R. Rogers, "Epidemiology and control of nosocomial fungal infections," Current Opinion in Infectious Diseases, vol. 8, no. 4, pp. 287-290, 1995.

[14] R. Ruchlemer, A. M. Yinnon, and C. Hershko, "Changes in the natural history of invasive pulmonary aspergillosis in neutropenic leukemic patients," Israel Journal of Medical Sciences, vol. 32, no. 11, pp. 1089-1092, 1996.

[15] G. P. Bodey and S. Vartivarian, "Aspergillosis," European Journal of Clinical Microbiology and Infectious Diseases, vol. 8, no. 5, pp. 413-437, 1989.

[16] V. T. Andriole, "Infections with Aspergillus species," Clinical Infectious Diseases, vol. 17, no. 2, pp. S481-S486, 1993.

[17] D. M. Dixon, M. M. McNeil, M. L. Cohen, B. G. Gellin, and J. R. La Montagne, "Fungal infections: a growing threat," Public Health Reports, vol. 111, no. 3, pp. 226-235, 1996.

[18] A. H. Groll, P. M. Shah, C. Mentzel, M. Schneider, G. JustNuebling, and K. Huebner, "Trends in the postmortem epidemiology of invasive fungal infections at a University Hospital," Journal of Infection, vol. 33, no. 1, pp. 23-32, 1996.

[19] D. W. Denning, "Invasive aspergillosis," Clinical Infectious Diseases, vol. 26, no. 4, pp. 781-805, 1998.

[20] V. P. Kurup and A. Kumar, "Immunodiagnosis of aspergillosis," Clinical Microbiology Reviews, vol. 4, no. 4, pp. 439-456, 1991.

[21] D. D. Dixon and T. J. Walsh, "Human pathogenesis," in Aspergillus, Biology and Industrial Application, J. W. Bennett and M. A. Klich, Eds., pp. 249-267, Butterworth-Heinemann, Boston, Mass, USA, 1992.

[22] A. Schaffner, "Host defense in aspergillosis," in New Strategies in Fungal Disease, J. E. Bennett, R. J. Hay, and P. K. Peterson, Eds., pp. 98-112, Churchill Livingstone, Edinburgh, UK, 1992.

[23] F. Derouin, "Diagnosis, treatment and prevention of invasive aspergillosis. A priority target in hospital units," Pathologie Biologie, vol. 42, no. 7, pp. 629-631, 1994.

[24] J. Latgé, “Aspergillus fumigatus and aspergillosis," Clinical Microbiology Reviews, vol. 12, no. 2, pp. 310-350, 1999.

[25] J. Seo, K. Han, and J. Yu, "Multiple roles of a heterotrimeric G-protein $\gamma$-subunit in governing growth and development of Aspergillus nidulans," Genetics, vol. 171, no. 1, pp. 81-89, 2005.

[26] J. Yu, "Heterotrimeric G protein signaling and RGSs in Aspergillus nidulans," Journal of Microbiology, vol. 44, no. 2, pp. 145-154, 2006.

[27] S. Rosén, J. Yu, and T. H. Adams, “The Aspergillus nidulans sfaD gene encodes a $\mathrm{G}$ protein $\beta$ subunit that is required for normal growth and repression of sporulation," The EMBO Journal, vol. 18 , no. 20, pp. 5592-5600, 1999.

[28] K. Shimizu and N. P. Keller, "Genetic involvement of a cAMPdependent protein kinase in a $G$ protein signaling pathway regulating morphological and chemical transitions in Aspergillus nidulans," Genetics, vol. 157, no. 2, pp. 591-600, 2001.

[29] H. S. Park and J. H. Yu, "Genetic control of asexual sporulation in filamentous fungi," Current Opinion in Microbiology, vol. 15, pp. 669-677, 2012.

[30] J. Yu, J. Wieser, and T. H. Adams, "The Aspergillus FlbA RGS domain protein antagonizes $\mathrm{G}$ protein signaling to block proliferation and allow development," The EMBO Journal, vol. 15, no. 19, pp. 5184-5190, 1996. 
[31] K. S. Shin, H. S. Park, Y. H. Kim, and J. H. Yu, "Comparative proteomic analyses reveal that FlbA down-regulates gliT expression and SOD activity in Aspergillus fumigatus," Journal of Proteomics, vol. 87, pp. 40-52, 2013.

[32] J. Seo and J. Yu, "The phosducin-like protein PhnA is required for $\mathrm{G} \beta \gamma$-mediated signaling for vegetative growth, developmental control, and toxin biosynthesis in Aspergillus nidulans," Eukaryotic Cell, vol. 5, no. 2, pp. 400-410, 2006.

[33] T. H. Adams, J. K. Wieser, and J. Yu, "Asexual sporulation in Aspergillus nidulans," Microbiology and Molecular Biology Reviews, vol. 62, no. 1, pp. 35-54, 1998.

[34] P. Krijgsheld, R. Bleichrodt, G. J. van Veluw et al., "Development in Aspergillus," Studies in Mycology, vol. 74, pp. 1-29, 2013.

[35] U. Kües and R. Fischer, "Asexual sporulation in mycelial fungi," in The Mycota: Growth, Differentiation and Sexuality, U. Kües and R. Fischer, Eds., vol. 1, pp. 263-292, Springer, 2006.

[36] H. Yang and G. B. Lucas, "Effects of $\mathrm{N}_{2}-\mathrm{O}_{2}$ and $\mathrm{CO}_{2}-\mathrm{O}_{2}$ tensions on growth of fungi isolated from damaged flue-cured tobacco," Applied Microbiology, vol. 19, no. 2, pp. 271-277, 1970.

[37] A. M. Calvo, "The VeA regulatory system and its role in morphological and chemical development in fungi," Fungal Genetics and Biology, vol. 45, no. 7, pp. 1053-1061, 2008.

[38] I. Skromne, O. Sanchez, and J. Aguirre, "Starvation stress modulates the expression of the Aspergillus nidulans brlA regulatory gene," Microbiology, vol. 141, no. 1, pp. 21-28, 1995.

[39] O. Etxebeste, E. Herrero-García, L. Araújo-Bazán et al., “The bZIP-type transcription factor FIbB regulates distinct morphogenetic stages of colony formation in Aspergillus nidulans," Molecular Microbiology, vol. 73, no. 5, pp. 775-789, 2009.

[40] T. Emri, Z. Molnár, M. Szilágyi, and I. Pócsi, "Regulation of autolysis in Aspergillus nidulans," Applied Biochemistry and Biotechnology, vol. 151, no. 2-3, pp. 211-220, 2008.

[41] T. H. Adams, M. T. Boylan, and W. E. Timberlake, "brlA is necessary and sufficient to direct conidiophore development in Aspergillus nidulans," Cell, vol. 54, no. 3, pp. 353-362, 1988.

[42] A. Andrianopoulos and W. E. Timberlake, "The Aspergillus nidulans abaA gene encodes a transcriptional activator that acts as a genetic switch to control development," Molecular and Cellular Biology, vol. 14, no. 4, pp. 2503-2515, 1994.

[43] T. C. Sewall, C. W. Mims, and W. E. Timberlake, "abaA controls phialide differentiation in Aspergillus nidulans," Plant Cell, vol. 2, no. 8, pp. 731-739, 1990.

[44] P. M. Mirabito, T. H. Adams, and W. E. Timberlake, "Interactions of three sequentially expressed genes control temporal and spatial specificity in Aspergillus development," Cell, vol. 57, no. 5, pp. 859-868, 1989.

[45] M. T. Boylan, P. M. Mirabito, C. E. Willett, C. R. Zimmerman, and W. E. Timberlake, "Isolation and physical characterization of three essential conidiation genes from Aspergillus nidulans," Molecular and Cellular Biology, vol. 7, no. 9, pp. 3113-3118, 1987.

[46] O. Etxebeste, A. Garzia, E. A. Espeso, and U. Ugalde, "Aspergillus nidulans asexual development: making the most of cellular modules," Trends in Microbiology, vol. 18, no. 12, pp. 569-576, 2010.

[47] P. Xiao, K. Shin, T. Wang, and J. Yu, “Aspergillus fumigatus flbB encodes two basic leucine zipper domain (bZIP) proteins required for proper asexual development and gliotoxin production," Eukaryotic Cell, vol. 9, no. 11, pp. 1711-1723, 2010.

[48] O. Etxebeste, M. Ni, A. Garzia et al., "Basic-zipper-type transcription factor FlbB controls asexual development in Aspergillus nidulans," Eukaryotic Cell, vol. 7, no. 1, pp. 38-48, 2008.
[49] N. Kwon, A. Garzia, E. A. Espeso, U. Ugalde, and J. Yu, "FlbC is a putative nuclear $\mathrm{C}_{2} \mathrm{H}_{2}$ transcription factor regulating development in Aspergillus nidulans," Molecular Microbiology, vol. 77, no. 5, pp. 1203-1219, 2010.

[50] J. Arratia-Quijada, O. Sánchez, C. Scazzocchio, and J. Aguirre, "FlbD, a Myb transcription factor of Aspergillus nidulans, is uniquely involved in both asexual and sexual differentiation," Eukaryotic Cell, vol. 11, pp. 1132-1142, 2012.

[51] J. Wieser and T. H. Adams, "flbD encodes a Myb-like DNAbinding protein that coordinates initiation of Aspergillus nidulans conidiophore development," Genes and Development, vol. 9, no. 4, pp. 491-502, 1995.

[52] N. Kwon, K. Shin, and J. Yu, "Characterization of the developmental regulator FlbE in Aspergillus fumigatus and Aspergillus nidulans," Fungal Genetics and Biology, vol. 47, no. 12, pp. 981993, 2010.

[53] A. Garzia, O. Etxebeste, E. Herrero-Garcia, R. Fischer, E. A. Espeso, and U. Ugalde, "Aspergillus nidulans FlbE is an upstream developmental activator of conidiation functionally associated with the putative transcription factor FlbB," Molecular Microbiology, vol. 71, no. 1, pp. 172-184, 2009.

[54] S. Jain and N. Keller, "Insights to fungal biology through LaeA sleuthing," Fungal Biology Reviews, vol. 27, pp. 51-59, 2013.

[55] S. S. Kim, Y. H. Kim, and K. S. Shin, "The developmental regulators, FlbB and FlbE, are involved in the virulence of Aspergillus fumigatus," Journal of Microbiology and Biotechnology, vol. 23, pp. 766-770, 2013.

[56] J. Wieser, B. N. Lee, J. W. Fondon III, and T. H. Adams, "Genetic requirements for initiating asexual development in Aspergillus nidulans," Current Genetics, vol. 27, no. 1, pp. 62-69, 1994.

[57] J. Mah and J. Yu, "Upstream and downstream regulation of asexual development in Aspergillus fumigatus," Eukaryotic Cell, vol. 5, no. 10, pp. 1585-1595, 2006.

[58] J. H. Yu, "Regulation and development of Aspergillus nidulans and Aspergillus fumigatus," Mycobiology, vol. 38, pp. 229-237, 2010.

[59] M. Ogawa, M. Tokuoka, F. J. Jin, T. Takahashi, and Y. Koyama, "Genetic analysis of conidiation regulatory pathways in kojimold Aspergillus oryzae," Fungal Genetics and Biology, vol. 47, no. 1, pp. 10-18, 2010.

[60] M. E. D. S. Ferreira, T. Heinekamp, A. Härtl et al., "Functional characterization of the Aspergillus fumigatus calcineurin," Fungal Genetics and Biology, vol. 44, no. 3, pp. 219-230, 2007.

[61] F. M. Soriani, I. Malavazi, M. E. Da Silva Ferreira et al., "Functional characterization of the Aspergillus fumigatus CRZ1 homologue, CrzA," Molecular Microbiology, vol. 67, no. 6, pp. 1274-1291, 2008.

[62] A. Spielvogel, H. Findon, H. N. Arst Jr. et al., "Two zinc finger transcription factors CrzA and SltA, are involved in cation homoeostasis and detoxification in Aspergillus nidulans," Biochemical Journal, vol. 414, no. 3, pp. 419-429, 2008.

[63] R. S. Almeida, O. Loss, A. C. Colabardini et al., "Genetic bypass of Aspergillus nidulanscrzA function in calcium homeostasis," Genes-Genomes-Genetics, vol. 3, pp. 1129-1141, 2013.

[64] P. K. Chang, "Aspergillus parasiticus $c r z A$, which encodes calcineurin response zinc-finger protein, is required for aflatoxin production under calcium stress," International Journal of Molecular Science, vol. 9, pp. 2027-2043, 2008.

[65] R. A. Cramer Jr., B. Z. Perfect, N. Pinchai et al., "Calcineurin target CrzA regulates conidial germination, hyphal growth, and pathogenesis of Aspergillus fumigatus," Eukaryotic Cell, vol. 7, no. 7, pp. 1085-1097, 2008. 
[66] Ö. Bayram, G. H. Braus, R. Fischer, and J. Rodriguez-Romero, "Spotlight on Aspergillus nidulans photosensory systems," Fungal Genetics and Biology, vol. 47, no. 11, pp. 900-908, 2010.

[67] J. Rodriguez-Romero, M. Hedtke, C. Kastner, S. Müller, and R. Fischer, "Fungi, hidden in soil or up in the air: light makes a difference," Annual Review of Microbiology, vol. 64, pp. 585-610, 2010.

[68] C. Ruger-Herreros, J. Rodríguez-Romero, R. FernándezBarranco et al., "Regulation of conidiation by light in Aspergillus nidulans," Genetics, vol. 188, no. 4, pp. 809-822, 2011.

[69] H. Jeong, H. Kim, D. Han, K. Jahng, and K. Chae, "Expression of the mnpA gene that encodes the mannoprotein of Aspergillus nidulans is dependent on fadA and flbA as well as veA," Fungal Genetics and Biology, vol. 38, no. 2, pp. 228-236, 2003.

[70] B. N. Lee and T. H. Adams, "The Aspergillus nidulans fluG gene is required for production of an extracellular developmental signal and is related to prokaryotic glutamine synthetase I," Genes and Development, vol. 8, no. 6, pp. 641-651, 1994.

[71] A. B. Rodríguez-Urra, C. Jiménez, M. I. Nieto, J. Rodríguez, H. Hayashi, and U. Ugalde, "Signaling the induction of sporulation involves the interaction of two secondary metabolites in Aspergillus nidulans," ACS Chemical Biology, vol. 7, no. 3, pp. 599-606, 2012.

[72] G. Soid-Raggi, O. Sánchez, and J. Aguirre, “TmpA, a member of a novel family of putative membrane flavoproteins, regulates asexual development in Aspergillus nidulans," Molecular Microbiology, vol. 59, no. 3, pp. 854-869, 2006.

[73] L. N. Yager, H. Lee, D. L. Nagle, and J. E. Zimmerman, "Analysis of fluG mutations that affect light-dependent conidiation in Aspergillus nidulans," Genetics, vol. 149, no. 4, pp. 1777-1786, 1998.

[74] J. L. Mooney, D. E. Hassett, and L. N. Yager, "Genetic analysis of suppressors of the veAl mutation in Aspergillus nidulans," Genetics, vol. 126, no. 4, pp. 869-874, 1990.

[75] P. K. Chang, L. L. Scharfenstein, B. Mack, and K. C. Ehrlich, "Deletion of the Aspergillus flavus orthologue of A. nidulans $f l u G$ reduces conidiation and promotes production of sclerotia but does not abolish aflatoxin biosynthesis," Applied Environmental Microbiology, vol. 78, pp. 7557-7563, 2012.

[76] J. Seo, Y. Guan, and J. Yu, "FluG-dependent asexual development in Aspergillus nidulans occurs via derepression," Genetics, vol. 172, no. 3, pp. 1535-1544, 2006.

[77] K. Han, J. Seo, and J. Yu, "Regulators of G-protein signalling in Aspergillus nidulans: RgsA downregulates stress response and stimulates asexual sporulation through attentuation of GanB (G $\alpha$ ) signalling," Molecular Microbiology, vol. 53, no. 2, pp. 529540, 2004.

[78] N. J. Kwon, H. S. Park, S. Jung, S. C. Kim, and J. H. Yu, “The putative guanine nucleotide exchange factor RicA mediates upstream signaling for growth and development in Aspergillus," Eukaryotic Cell, vol. 11, pp. 1399-1412, 2012.

[79] T. H. Adams, W. A. Hide, L. N. Yager, and B. N. L. Bee Na Lee, "Isolation of a gene required for programmed initiation of development by Aspergillus nidulans," Molecular and Cellular Biology, vol. 12, no. 9, pp. 3827-3833, 1992.

[80] B. M. Nitsche, T. R. Jørgensen, M. Akeroyd, V. Meyer, and A. F. J. Ram, "The carbon starvation response of Aspergillus niger during submerged cultivation: insights from the transcriptome and secretome," BMC Genomics, vol. 13, article 380, 2012.

[81] M. Szilágyi, M. Miskei, Z. Karányi, B. Lenkey, I. Pócsi, and T. Emri, "Transcriptome changes initiated by carbon starvation in Aspergillus nidulans," Microbiology, vol. 159, pp. 176-190, 2013.
[82] B. N. Lee and T. H. Adams, "Overexpression of flbA, an early regulator of Aspergillus asexual sporulation, leads to activation of brlA and premature initiation of development," Molecular Microbiology, vol. 14, no. 2, pp. 323-334, 1994.

[83] S. P. Champe, D. L. Nagle, and L. N. Yager, "Sexual sporulation," Progress in Industrial Microbiology, vol. 29, pp. 429-454, 1994.

[84] H. Kim, K. Chae, K. Han, and D. Han, “The nsdC gene encoding a putative $\mathrm{C}_{2} \mathrm{H}_{2}$-type transcription factor is a key activator of sexual development in Aspergillus nidulans," Genetics, vol. 182, no. 3, pp. 771-783, 2009.

[85] K. Han, K. Han, J. Yu, K. Chae, K. Jahng, and D. Han, "The nsdD gene encodes a putative GATA-type transcription factor necessary for sexual development of Aspergillus nidulans," Molecular Microbiology, vol. 41, no. 2, pp. 299-309, 2001.

[86] J. W. Cary, P. Y. Harris-Coward, K. C. Ehrlich et al., "NsdC and NsdD affect Aspergillus flavus morphogenesis and aflatoxin production," Eukaryotic Cell, vol. 11, pp. 1104-1111, 2012.

[87] K. Han, J. H. Kim, H. Moon et al., "The Aspergillus nidulans esdC (early sexual development) gene is necessary for sexual development and is controlled by veA and a heterotrimeric $\mathrm{G}$ protein," Fungal Genetics and Biology, vol. 45, no. 3, pp. 310-318, 2008.

[88] B. Levine and D. J. Klionsky, "Development by self-digestion: molecular mechanisms and biological functions of autophagy," Developmental Cell, vol. 6, no. 4, pp. 463-477, 2004.

[89] T. Emri, Z. Molnár, and I. Pócsi, “The appearances of autolytic and apoptotic markers are concomitant but differently regulated in carbon-starving Aspergillus nidulans cultures," FEMS Microbiology Letters, vol. 251, no. 2, pp. 297-303, 2005.

[90] T. Yorimitsu and D. J. Klionsky, "Autophagy: molecular machinery for self-eating," Cell Death and Differentiation, vol. 12, no. 2, pp. 1542-1552, 2005.

[91] D. L. Richie and D. S. Askew, "Autophagy in the filamentous fungus Aspergillus fumigatus," Methods in enzymology, vol. 451, pp. 241-250, 2008.

[92] M. McIntyre, D. R. Berry, and B. McNeil, "Response of Penicillium chrysogenum to oxygen starvation in glucose- and nitrogen-limited chemostat cultures," Enzyme and Microbial Technology, vol. 25, no. 3-5, pp. 447-454, 1999.

[93] B. M. Nitsche, A. M. Burggraaf-van Welzen, G. Lamers, V. Meyer, and A. F. Ram, "Autophagy promotes survival in aging submerged cultures of the filamentous fungus Aspergillus niger," Applied Microbiology and Biotechnology, 2013.

[94] S. White, M. McIntyre, D. R. Berry, and B. McNeil, "The autolysis of industrial filamentous fungi," Critical Reviews in Biotechnology, vol. 22, no. 1, pp. 1-14, 2002.

[95] T. Emri, Z. Molnár, T. Pusztahelyi, and I. Pócsi, "Physiological and morphological changes in autolyzing Aspergillus nidulans cultures," Folia Microbiologica, vol. 49, no. 3, pp. 277-284, 2004.

[96] T. Emri, Z. Molnár, T. Veres, T. Pusztahelyi, G. Dudás, and I. Pócsi, "Glucose-mediated repression of autolysis and conidiogenesis in Emericella nidulans," Mycological Research, vol. 110, no. 10, pp. 1172-1178, 2006.

[97] T. Pusztahelyi, I. Pócsi, J. Kozma, and A. Szentirmai, "Aging of Penicillium chrysogenum cultures under carbon starvation: I: morphological changes and secondary metabolite production," Biotechnology and Applied Biochemistry, vol. 25, no. 1, pp. 81-86, 1997.

[98] I. Pócsi, T. Pusztahelyi, L. Sámi, and T. Emri, "Autolysis of Penicillium chrysogenum - a holistic approach," Indian Journal of Biotechnology, vol. 2, no. 3, pp. 293-301, 2003. 
[99] R. A. Shroff, S. M. O’Connor, M. J. Hynes, R. A. Lockington, and J. M. Kelly, "Null alleles of creA, the regulator of carbon catabolite repression in Aspergillus nidulans," Fungal Genetics and Biology, vol. 22, no. 1, pp. 28-38, 1997.

[100] J. O. Nehlin and H. Ronne, "Yeast MIG1 repressor is related to the mammalian early growth response and Wilms' tumour finger proteins," The EMBO Journal, vol. 9, no. 9, pp. 2891-2898, 1990.

[101] M. Mathieu and B. Felenbok, "The Aspergillus nidulans CREA protein mediates glucose repression of the ethanol regulon at various levels through competition with the ALCR-specific transactivator," The EMBO Journal, vol. 13, no. 17, pp. 4022-4027, 1994.

[102] R. A. Shroff, R. A. Lockington, and J. M. Kelly, "Analysis of mutations in the creA gene involved in carbon catabolite depression in Aspergillus nidulans," Canadian Journal of Microbiology, vol. 42, no. 9, pp. 950-959, 1996.

[103] I. Pócsi, É. Leiter, N.-J. Kwon et al., "Asexual sporulation signalling regulates autolysis of Aspergillus nidulans via modulating the chitinase ChiB production," Journal of Applied Microbiology, vol. 107, no. 2, pp. 514-523, 2009.

[104] H. Yamazaki, D. Yamazaki, N. Takaya, M. Takagi, A. Ohta, and $\mathrm{H}$. Horiuchi, "A chitinase gene, chiB, involved in the autolytic process of Aspergillus nidulans," Current Genetics, vol. 51, no. 2, pp. 89-98, 2007.

[105] M. Szilágyi, N.-J. Kwon, C. Dorogi, I. Pócsi, J.-H. Yu, and T. Emri, "The extracellular $\beta$-1,3-endoglucanase EngA is involved in autolysis of Aspergillus nidulans," Journal of Applied Microbiology, vol. 109, no. 5, pp. 1498-1508, 2010.

[106] J. Kamerewerd, I. Zadra, H. Kürnsteiner, and U. Kück, "PcchiB1, encoding a class V chitinase, is affected by PcVelA and PcLaeA, and is responsible for cell wall integrity in Penicillium chrysogenum," Microbiology, vol. 157, no. 11, pp. 3036-3048, 2011.

[107] A. Sharon, A. Finkelstein, N. Shlezinger, and I. Hatam, "Fungal apoptosis: function, genes and gene function," FEMS Microbiology Reviews, vol. 33, no. 5, pp. 833-854, 2009.

[108] É. Leiter, H. Szappanos, C. Oberparleiter et al., "Antifungal protein PAF severely affects the integrity of the plasma membrane of Aspergillus nidulans and induces an apoptosis-like phenotype," Antimicrobial Agents and Chemotherapy, vol. 49, no. 6, pp. 2445-2453, 2005.

[109] F. Marx, U. Binder, É. Leiter, and I. Pócsi, “The Penicillium chrysogenum antifungal protein PAF, a promising tool for the development of new antifungal therapies and fungal cell biology studies," Cellular and Molecular Life Sciences, vol. 65, no. 3, pp. 445-454, 2008.

[110] U. Binder, C. Oberparleiter, V. Meyer, and F. Marx, "The antifungal protein PAF interferes with $\mathrm{PKC} / \mathrm{MPK}$ and $\mathrm{CAMP} / \mathrm{PKA}$ signalling of Aspergillus nidulans," Molecular Microbiology, vol. 75, no. 2, pp. 294-307, 2010.

[111] Y. Q. Zhang, H. Wilkinson, Keller, and N. P. Tsitsigiannis D, "Secondary metabolite gene clusters," in Handbook of Industrial Mycology, Z. An, Ed., pp. 355-386, 2004.

[112] J. Yu and N. Keller, "Regulation of secondary metabolism in filamentous fungi," Annual Review of Phytopathology, vol. 43, pp. 437-458, 2005.

[113] M. J. Sweeney and A. D. W. Dobson, "Molecular biology of mycotoxin biosynthesis," FEMS Microbiology Letters, vol. 175, no. 2, pp. 149-163, 1999.

[114] J. Yu, "Current understanding on aflatoxin biosynthesis and future perspective in reducing aflatoxin contamination," Toxins, vol. 4, pp. 1024-1057, 2012.
[115] N. P. Keller and T. H. Adams, "Analysis of a mycotoxin gene cluster in Aspergillus nidulans," SAAS Bulletin, Biochemistry and Biotechnology, vol. 8, pp. 14-21, 1995.

[116] N. P. Keller and T. M. Hohn, "Metabolic pathway gene clusters in filamentous fungi," Fungal Genetics and Biology, vol. 21, no. 1, pp. 17-29, 1997.

[117] D. W. Brown, J.-H. Yu, H. S. Kelkar et al., "Twenty-five coregulated transcripts define a sterigmatocystin gene cluster in Aspergillus nidulans," Proceedings of the National Academy of Sciences of the United States of America, vol. 93, no. 4, pp. 14181422, 1996.

[118] J. Yu, P. Chang, K. C. Ehrlich et al., "Clustered Pathway Genes in Aflatoxin Biosynthesis," Applied and Environmental Microbiology, vol. 70, no. 3, pp. 1253-1262, 2004.

[119] J. Yu, R. A. E. Butchko, M. Fernandes, N. P. Keller, T. J. Leonard, and T. H. Adams, "Conservation of structure and function of the aflatoxin regulatory gene aflR from Aspergillus nidulans and A. flavus," Current Genetics, vol. 29, no. 6, pp. 549-555, 1996.

[120] J. K. Hicks, J. Yu, N. P. Keller, and T. H. Adams, “Aspergillus sporulation and mycotoxin production both require inactivation of the FadA G $\alpha$ protein-dependent signaling pathway," The EMBO Journal, vol. 16, no. 16, pp. 4916-4923, 1997.

[121] K. Shimizu, J. K. Hicks, T. Huang, and N. P. Keller, "Pka, Ras and RGS protein interactions regulate activity of aflR, a $\mathrm{Zn}(\mathrm{II}) 2 \mathrm{Cys} 6$ transcription factor in Aspergillus nidulans," Genetics, vol. 165, no. 3, pp. 1095-1104, 2003.

[122] M. Brodhagen and N. P. Keller, "Signalling pathways connecting mycotoxin production and sporulation," Molecular Plant Pathology, vol. 7, no. 4, pp. 285-301, 2006.

[123] A. Tag, J. Hicks, G. Garifullina et al., "G-protein signalling mediates differential production of toxic secondary metabolites," Molecular Microbiology, vol. 38, no. 3, pp. 658-665, 2000.

[124] L. V. Roze, R. M. Beaudry, N. P. Keller, and J. E. Linz, "Regulation of aflatoxin synthesis by FadA/cAMP/protein kinase A signaling in Aspergillus parasiticus," Mycopathologia, vol. 158, no. 2, pp. 219-232, 2004.

[125] D. M. Meyers, G. Obrian, W. L. Du, D. Bhatnagar, and G. A. Payne, "Characterization of aflJ, a gene required for conversion of pathway intermediates to aflatoxin," Applied and Environmental Microbiology, vol. 64, no. 10, pp. 3713-3717, 1998.

[126] P.-K. Chang, "The Aspergillus parasiticus protein AFLJ interacts with the aflatoxin pathway-specific regulator aflR," Molecular Genetics and Genomics, vol. 268, no. 6, pp. 711-719, 2003.

[127] J. Purschwitz, S. Müller, C. Kastner et al., "Functional and physical interaction of blue- and red-light sensors in Aspergillus nidulans," Current Biology, vol. 18, no. 4, pp. 255-259, 2008.

[128] A. Atoui, C. Kastner, C. M. Larey et al., "Cross-talk between light and glucose regulation controls toxin production and morphogenesis in Aspergillus nidulans," Fungal Genetics and Biology, vol. 47, no. 12, pp. 962-972, 2010.

[129] N. Kato, W. Brooks, and A. M. Calvo, "The expression of sterigmatocystin and penicillin genes in Aspergillus nidulans is controlled by veA, a gene required for sexual development," Eukaryotic Cell, vol. 2, no. 6, pp. 1178-1186, 2003.

[130] J. W. Bok and N. P. Keller, "LaeA, a regulator of secondary metabolism in Aspergillus spp.," Eukaryotic Cell, vol. 3, no. 2, pp. 527-535, 2004.

[131] R. M. Perrin, N. D. Fedorova, J. W. Bok et al., "Transcriptional regulation of chemical diversity in Aspergillus fumigatus by LaeA," PLoS pathogens, vol. 3, no. 4, p. e50, 2007. 
[132] S. P. Kale, L. Milde, M. K. Trapp, J. C. Frisvad, N. P. Keller, and J. W. Bok, "Requirement of LaeA for secondary metabolism and sclerotial production in Aspergillus flavus," Fungal Genetics and Biology, vol. 45, no. 10, pp. 1422-1429, 2008.

[133] Y. Reyes-Dominguez, J. W. Bok, H. Berger et al., "Heterochromatic marks are associated with the repression of secondary metabolism clusters in Aspergillus nidulans," Molecular Microbiology, vol. 76, no. 6, pp. 1376-1386, 2010.

[134] J. M. Palmer, J. M. Theisen, R. M. Duran, W. S. Grayburn, A. M. Calvo, and N. P. Keller, "Secondary metabolism and development is mediated by LlmF control of VeA subcellular localization in Aspergillus nidulans," PLoS Genetics, vol. 9, Article ID e1003193, 2013.

[135] M. I. Shaaban, J. W. Bok, C. Lauer, and N. P. Keller, "Suppressor mutagenesis identifies a velvet complex remediator of Aspergillus nidulans secondary metabolism," Eukaryotic Cell, vol. 9, no. 12, pp. 1816-1824, 2010.

[136] Ö. Bayram and G. H. Braus, "Coordination of secondary metabolism and development in fungi: the velvet family of regulatory proteins," FEMS Microbiology Reviews, vol. 36, no. 1, pp. 1-24, 2012.

[137] W. B. Yin, A. W. Reinke, M. Szilágyi et al., "bZIP transcription factors affecting secondary metabolism, sexual development and stress responses in Aspergillus nidulans," Microbiology, vol. 159, pp. 77-88, 2013.

[138] P.-K. Chang, J. W. Cary, J. Yu, D. Bhatnagar, and T. E. Cleveland, "The Aspergillus parasiticus polyketide synthase gene pksA, a homolog of Aspergillus nidulans wA, is required for aflatoxin B1 biosynthesis," Molecular and General Genetics, vol. 248, no. 3, pp. 270-277, 1995.

[139] K. C. Ehrlich, B. G. Montalbano, and P. J. Cotty, "Sequence comparison of aflR from different Aspergillus species provides evidence for variability in regulation of aflatoxin production," Fungal Genetics and Biology, vol. 38, no. 1, pp. 63-74, 2003. 

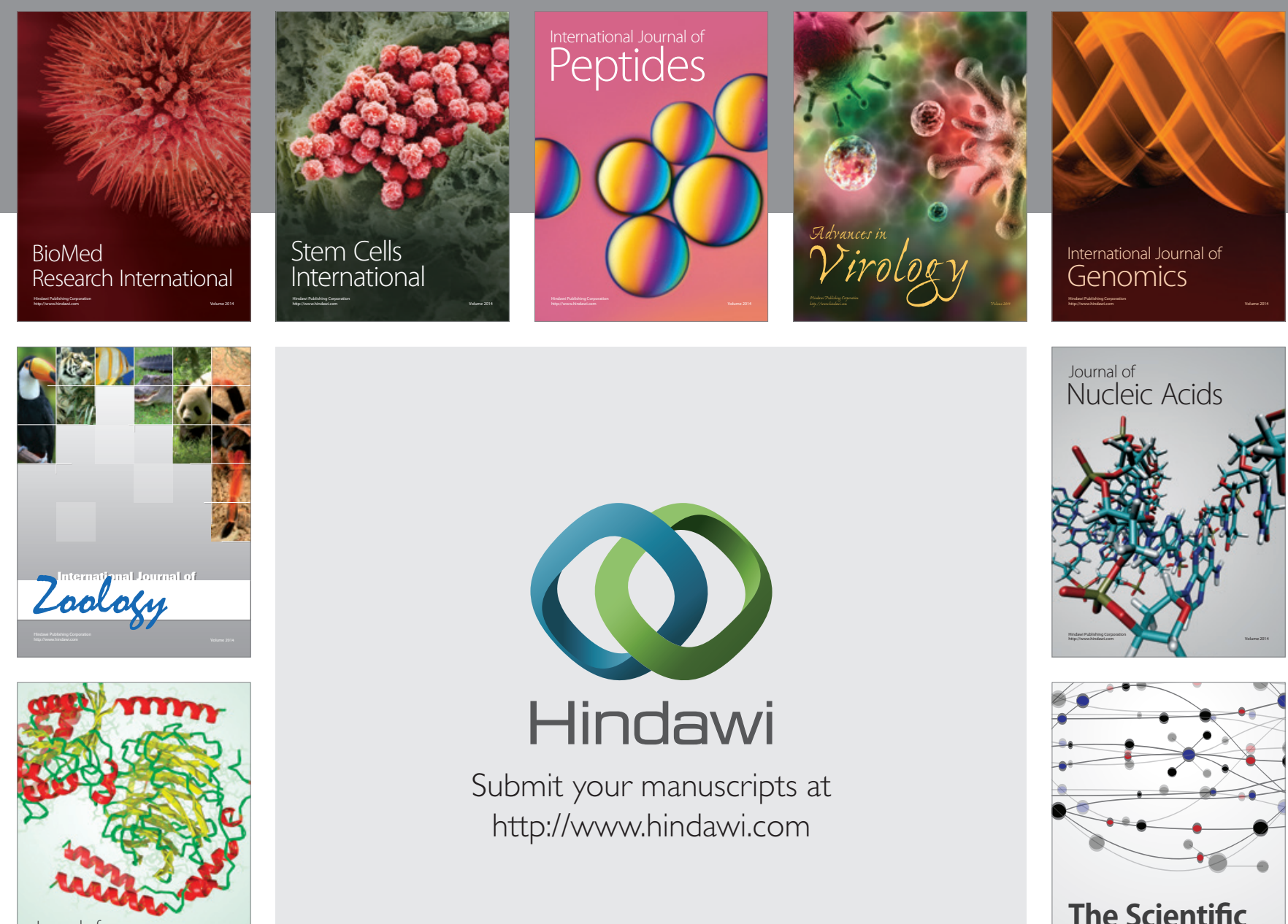

Submit your manuscripts at

http://www.hindawi.com

Journal of
Signal Transduction
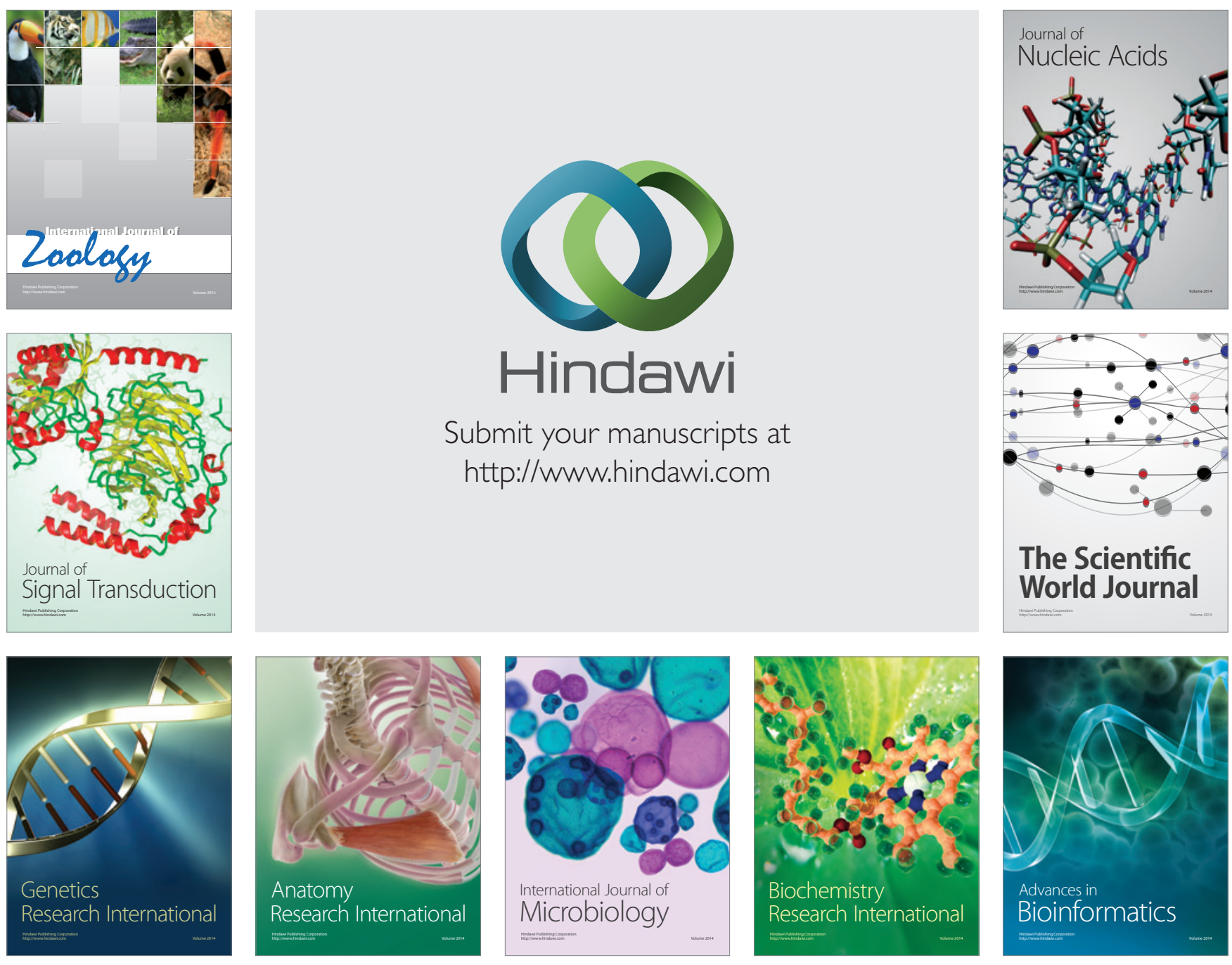

The Scientific World Journal
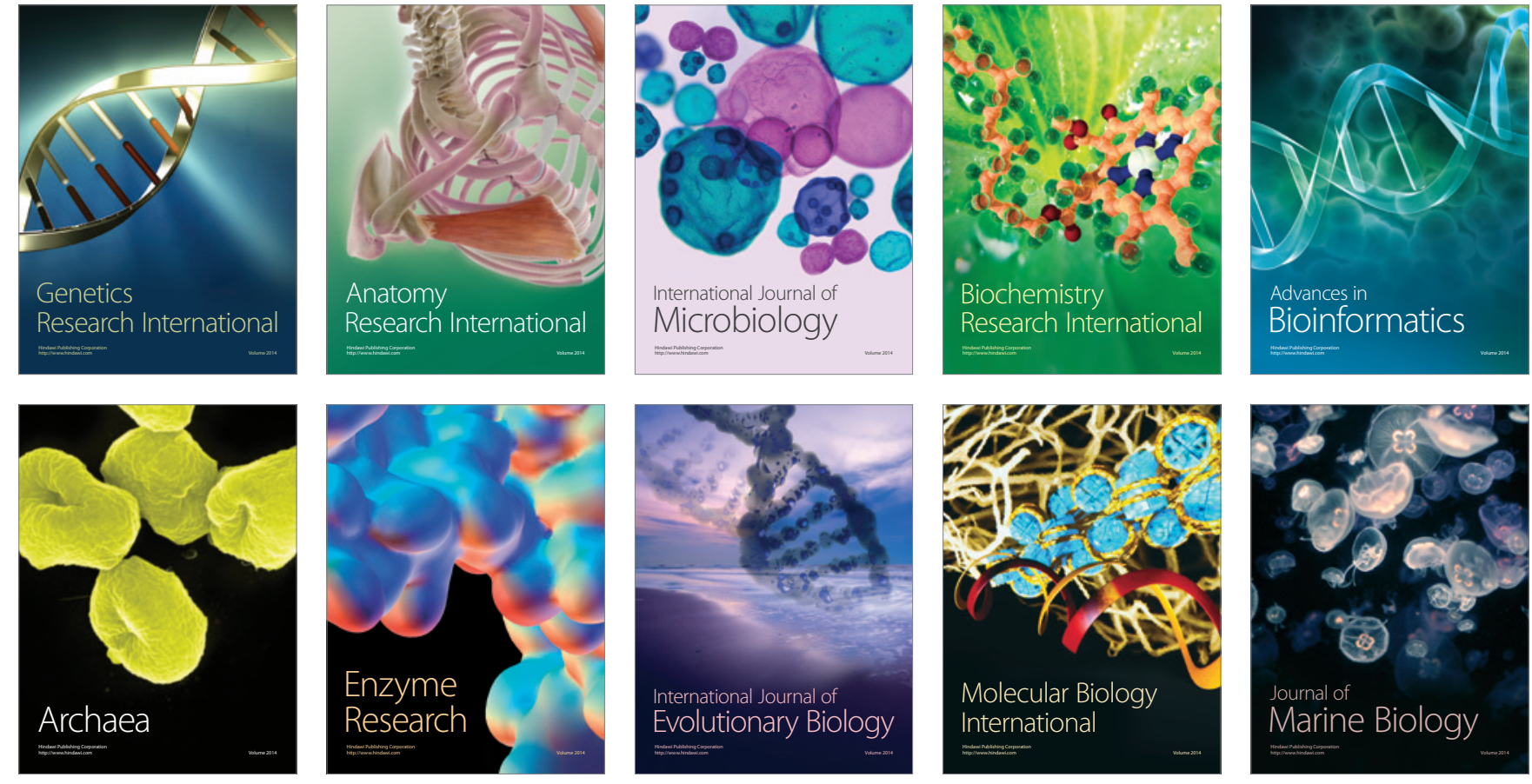